\title{
Sex Differences by Hospital-Level in Performance and Outcomes of Endovascular Treatment for Acute Ischemic Stroke
}

\author{
Soledad Pérez-Sánchez, ${ }^{\mathrm{a}, \mathrm{b}}$ Ana Barragán-Prieto, ,ab Joaquín Ortega-Quintanilla, b,c \\ Ana Domínguez-Mayoral, ${ }^{\mathrm{a}, \mathrm{b}}$ Miguel Ángel Gamero-García, ${ }^{\mathrm{a}, \mathrm{b}}$ Elena Zapata-Arriaza, ${ }^{\mathrm{b}, \mathrm{c}}$ \\ Reyes de Torres-Chacón, ${ }^{\mathrm{a}, \mathrm{b}}$ Asier de Albóniga-Chindurza, ${ }^{\mathrm{b}, \mathrm{c}}$ Montserrat Zapata-Hidalgo, ${ }^{\mathrm{b}}$ \\ Francisco Moniche, ${ }^{\mathrm{b}, \mathrm{d}}$ Irene Escudero-Martínez, ${ }^{\mathrm{b}, \mathrm{d}}$ Pablo Baena, ${ }^{\mathrm{b}, \mathrm{d}}$ Juan Antonio Cabezas, ${ }^{\mathrm{b}, \mathrm{d}}$ \\ Juan Miguel Oropesa-Ruiz, , Gema Sanz-Fernández, ${ }^{\mathrm{e}}$ Alejandro González, ${ }^{\mathrm{b}, \mathrm{c}}$ Joan Montaner ${ }^{\mathrm{a}, \mathrm{b}}$ \\ aDepartment of Neurology, University Hospital Virgen Macarena, Sevilla, Spain \\ ${ }^{b}$ Neurovascular Research Laboratory, Institute of Biomedicine of Seville-lbiS, Sevilla, Spain \\ 'Department of Radiology, Interventional Neuroradiology, University Hospital Virgen del Rocío, Sevilla, Spain \\ dDepartment of Neurology, University Hospital Virgen del Rocío, Sevilla, Spain \\ eDepartment of Neurology, University Hospital Juan Ramón Jiménez, Huelva, Spain
}

\section{Dear Sir:}

The clinical outcome of stroke differs between sexes, representing the first cause of death in women globally. ${ }^{1}$ Studies showing differences in the results of endovascular therapy and thrombectomy according to sex are limited and have not been systematically explored. ${ }^{2}$ In fact, those studies have not explored the impact of sex in relation to the speed of accessing reperfusion therapies. Moreover, stroke care differs between community and tertiary hospitals, mainly due to difficult access to health resources. However, sex disparities by type of hospital have not been previously explored.

A prospective and multi-center registry was conducted to explore the clinical results according to the sex of patients with anterior circulation ischemic strokes treated with endovascular treatment (approved by the Institutional Review Board of every participating hospital, internal code 0992-N-17). Moreover, we investigated whether stroke women are attended in a similar way than men in those nine hospitals network referring to our comprehensive stroke center, regarding the type of hospital and the presence or not of stroke units (SUs) with specialized stroke physicians in those referring centers.

Demographic data and clinical characteristics of stroke were registered. We collected data regarding the presence of previ- ous recombinant tissue plasminogen activator (rtPA) administration. Treatment intervals were measured in each phase of the process (door to brain imaging time, door to needle time, computed tomography [CT] to needle time, door to arterial puncture time, and puncture to recanalization time).

Angiographic results were measured by the modified Thrombolysis in Cerebral Infarction (mTICl) scale. Recanalization success was defined as $\mathrm{mTICl}$ grade $2 b-3$. Functional outcomes were evaluated with the modified Rankin Scale (mRS) at 90 days.

A total of 492 stroke patients treated using endovascular therapies were included, of which 220 were women. Women were older than men $(75 \pm 13$ years vs. $67 \pm 13$ years, $P=0.001)$. Three hundred twenty-three patients (65.65\%) came from hospitals with SU. The complete clinical characteristics according to sex are shown in Table 1.

There was no statistical difference in previous rtPA treatment between the groups $(41.1 \%$ in women vs. $46 \%$ in men, $P=0.281)$. With regard to treatment intervals, there were differences in door to CT time $(49.49 \pm 110.61$ minutes in women vs. $33.13 \pm 52.70$ minutes in men, $P=0.042)$ and in door to needle time $(64.78 \pm 45.61$ minutes in women vs. $51.76 \pm 30.41$ minutes in men, $P=0.022$ ) in patients with previous rtPA administration. Longer delays in treatment administration, espe- 
Table 1. Clinical characteristics according to patient sex

\begin{tabular}{|c|c|c|c|}
\hline Characteristic & Women $(n=220)$ & Men $(n=272)$ & $P$ \\
\hline Age (yr) & $75 \pm 13$ & $67 \pm 13$ & 0.001 \\
\hline \multicolumn{4}{|l|}{ Medical history } \\
\hline Atrial fibrillation/flutter & $75(34.1)$ & $62(22.8)$ & 0.005 \\
\hline Diabetes mellitus & $52(23.7)$ & $90(33.1)$ & 0.021 \\
\hline Hypertension & 167 (75.9) & $190(69.8)$ & 0.134 \\
\hline Hyperlipidemia & $100(45.5)$ & $127(46.7)$ & 0.784 \\
\hline Obesity (BMI > 30 kg/m²) & $68(30.9)$ & $62(22.8)$ & 0.042 \\
\hline Smoker & $25(11.4)$ & $82(30.2)$ & $<0.001$ \\
\hline Alcohol intake & $4(1.8)$ & $57(20.9)$ & $<0.001$ \\
\hline Prior stroke/transient ischemic attack & $38(27.3)$ & $48(17.7)$ & 0.913 \\
\hline Previous myocardial infarction & $27(12.3)$ & $66(24.3)$ & 0.001 \\
\hline Peripheral vascular disease & $3(1.4)$ & $22(8.1)$ & 0.001 \\
\hline Chronic kidney disease & $17(7.7)$ & $19(7.0)$ & 0.753 \\
\hline \multicolumn{4}{|l|}{ Medication use at baseline } \\
\hline Anticoagulants & $46(20.9)$ & $43(15.8)$ & 0.144 \\
\hline Aspirin & $64(29.1)$ & $102(37.8)$ & 0.043 \\
\hline Clopidogrel & $17(7.7)$ & $11(4.1)$ & 0.083 \\
\hline Statin & $77(35.2)$ & $106(39.1)$ & 0.368 \\
\hline Angiotensin-converting enzyme inhibitors or angiotensin receptors blockers & $80(36.5)$ & $82(30.0)$ & 0.127 \\
\hline Stroke etiology & & & $<0.001$ \\
\hline Atherotrombotic & $35(16.1)$ & $111(41.7)$ & \\
\hline Cardioembolic & $134(61.7)$ & $103(38.7)$ & \\
\hline Other & $48(22.1)$ & $52(19.5)$ & \\
\hline \multicolumn{4}{|l|}{ Pre-stroke center type } \\
\hline Hospitals with stroke unit & $146(66.3)$ & $177(65.1)$ & 0.451 \\
\hline \multicolumn{4}{|l|}{ Clinical characteristics at presentation } \\
\hline NIHSS at admission & $16 \pm 6$ & $15 \pm 6$ & 0.067 \\
\hline Pre-stroke $\mathrm{mRS} \leq 2$ & $204(92.7)$ & $263(96.7)$ & 0.047 \\
\hline SPAN-100 (stroke prognostication using age and NIHSS) & $90.9 \pm 15$ & $82.7 \pm 15$ & $<0.001$ \\
\hline \multicolumn{4}{|l|}{ Clinical outcomes } \\
\hline Mortality & $27(11.7)$ & $21(7.5)$ & 0.103 \\
\hline Intracranial hemorrhage & $36(17.8)$ & $34(14.3)$ & 0.312 \\
\hline NIHSS post-procedure & $13 \pm 7$ & $12 \pm 8$ & 0.010 \\
\hline NIHSS at discharge & $7 \pm 8$ & $6 \pm 7$ & 0.133 \\
\hline $\mathrm{mRS} \leq 2$ at 90 days & 184 (78.8) & $202(86.3)$ & 0.042 \\
\hline
\end{tabular}

Values are presented as mean \pm standard deviation or number (\%).

BMI, body mass index; NIHSS, National Institute of Health Stroke Score; mRS, modified Rankin Scale.

cially in women, were found in hospitals without SU (Figure 1).

There were no differences in terms of the successful of recanalization according to sex (88.2\% in women vs. $91.0 \%$ in men, $P=0.166)$. The proportion of patients with $\mathrm{mRS}$ score $\leq 2$ at 90 days was lower in women (78.8\%) than in men (86.3\%) $(P=0.042)$. In fact, being a woman increased the odds of having a bad functional outcome (odds ratio [OR], 1.66; 95\% confi- dence interval $[\mathrm{Cl}], 1$ to 2.76 ; $P=0.048)$, however, these differences were lost after age adjustment $(\mathrm{OR}, 1.2 ; 95 \% \mathrm{Cl}, 0.73$ to 2.13; $P=0.43$ ). Women from hospitals without SU had the lowest rate of independency at 90 days $(61.7 \%$ in women from hospitals without SU vs. $76.84 \%$ in women from hospitals with $\mathrm{SU}, P=0.023)$. We observed in the univariate analysis that being a woman doubled the odds of becoming dependent at those 


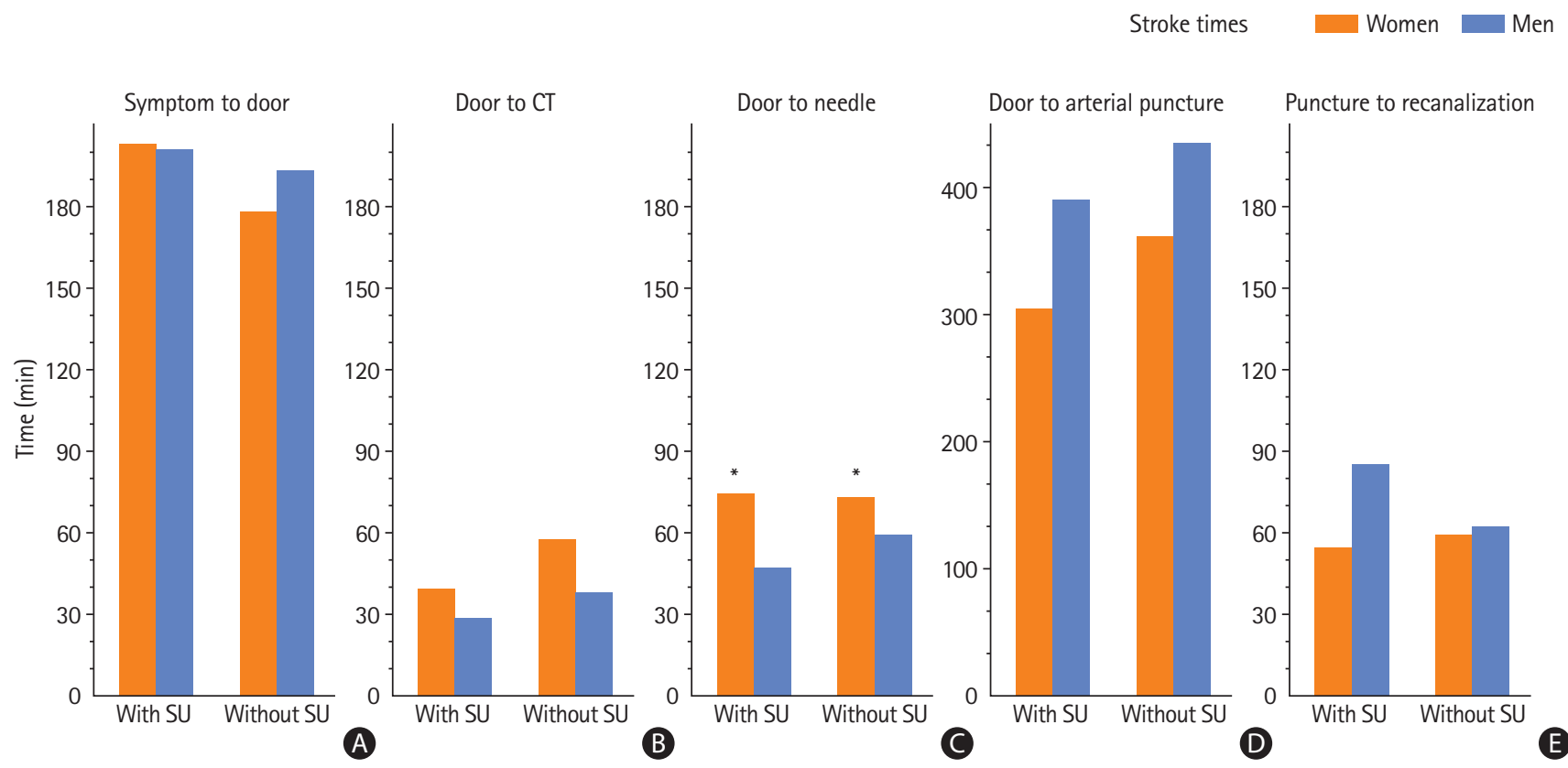

Figure 1. Treatment intervals according to sex and patient origin (with or without stroke unit [SU]). (A) Symptom to door, (B) door to computed tomography (CT), (C) door to needle, (D) door to arterial puncture, and (E) puncture to recanalization. ${ }^{*} P<0.05$.

hospitals (OR, 2.09; 95\% Cl, 1.09 to $4.03 ; P=0.027)$, and that was true even after age adjustment $(\mathrm{OR}, 1.98 ; 95 \% \mathrm{Cl}, 1.02$ to 3.84; $P=0.044)$. No differences were found in mortality rate by sex $(11.7 \%$ in women vs. $7.5 \%$ in men, $P=0.103)$ or by hospital-level.

It is widely accepted that functional outcomes after a stroke are worse in women. ${ }^{1}$ Regarding differences in healthcare provision between sexes, our data shows that there are important differences in the management of stroke by sex in our environment, especially in the door to needle time. Previous studies have shown that women are less likely to receive acute treatment, ${ }^{3}$ but only few studies about sex differences in door to needle times among rtPA-treated patients are available with different results. ${ }^{4}$

Our study also showed that community hospitals without specialized care are where the greatest differences exist between men and women in both management and outcomes. Stroke center type contributes to the underutilization of rtPA and also was an important hospital-level predictor of door to needle times in previous studies, with a higher proportion of patients treated within 60 minutes in hospitals with comprehensive stroke centers. ${ }^{5}$

One of the underlying reasons for this fact may be that nonspecific symptoms are more common in women, which makes the diagnosis of stroke more difficult to perform, even more in centers without specialists stroke physicians. These delays in women have been published previously but there are no well-designed studies to elucidate the reasons behind that fact. ${ }^{2}$ However, whether less attention is paid to women arriving with such symptoms to the emergency department remains a plausible explanation.

As for endovascular treatment variables, no differences were found in puncture to recanalization time and recanalization rates. This fact could reflect that the procedure is automatically performed independently of patient sex. Studies examining sex differences in recanalization or outcomes after endovascular treatment in stroke are lacking. Several secondary analyses of 90-day outcomes according to sex using data from randomized clinical trials ${ }^{6}$ and also real-world studies ${ }^{3,7,8}$ have been done with different results.

Our data shows that women are likely to have worse prognosis in terms of disability. This difference is even greater in patients from hospitals without SU. In fact, despite the effect of age in women's outcome (women are older), in these centers female sex is an independent predictive factor for dependency at 90 days as it remains after age adjustment. Fewer patients attended, the lack of specific protocols and specialized stroke physicians may also contribute to sex differences among these centers.

Our findings showed a disparity in stroke care according to sex, which was larger in hospitals without specialized stroke care. Despite being an observational study, our study shows for 
the first time that hospital-level has an influence on sex disparities outcomes after endovascular treatment. It also includes the largest number of patients until now, which allow us to conclude that women might have worse results than men after endovascular treatment since they arrive later to those therapies.

Strict adherence to protocols, training, and specialization of care could decrease these differences and improve stroke prognosis among women. This picture of real world will encourage clinicians dealing with this population to develop protocols in those centers where they are lacking in order to improve the care of female patients and remove disparities. In fact, prospective studies designed with specific interventions for this purpose are needed and might be complementary to standard reperfusion therapies.

\section{References}

1. Giralt $D$, Domingues-Montanari $S$, Mendioroz M, Ortega $L$, Maisterra 0, Perea-Gainza $M$, et al. The gender gap in stroke: a meta-analysis. Acta Neurol Scand 2012;125:83-90.

2. Bushnell C, Howard VJ, Lisabeth $L$, Caso V, Gall S, Kleindorfer $D$, et al. Sex differences in the evaluation and treatment of acute ischaemic stroke. Lancet Neurol 2018;17:641-650.

3. Uchida K, Yoshimura S, Sakai N, Yamagami H, Morimoto T. Sex differences in management and outcomes of acute ischemic stroke with large vessel occlusion. Stroke 2019;50:1915-1918.

4. Nagaraja N, Bhattacharya P, Mada F, Salowich-Palm L, Hinton $\mathrm{S}$, Millis $\mathrm{S}$, et al. Gender based differences in acute stroke care in Michigan hospitals. J Neurol Sci 2012;314:88-91.
5. Fonarow GC, Smith EE, Saver JL, Reeves MJ, Bhatt DL, GrauSepulveda MV, et al. Timeliness of tissue-type plasminogen activator therapy in acute ischemic stroke: patient characteristics, hospital factors, and outcomes associated with door-to-needle times within 60 minutes. Circulation 2011;123:750-758.

6. Chalos V, de Ridder IR, Lingsma HF, Brown $S$, van Oostenbrugge $\mathrm{RJ}$, Goyal $\mathrm{M}$, et al. Does sex modify the effect of endovascular treatment for ischemic stroke? Stroke 2019;50:24132419.

7. Carvalho A, Cunha A, Gregório T, Paredes L, Costa H, Veloso $M$, et al. Is the efficacy of endovascular treatment for acute ischemic stroke sex-related. Interv Neurol 2018;7:42-47.

8. Madsen TE, DeCroce-Movson E, Hemendinger M, McTaggart RA, Yaghi $S$, Cutting $S$, et al. Sex differences in 90-day outcomes after mechanical thrombectomy for acute ischemic stroke. J Neurointerv Surg 2019;11:221-225.

Correspondence: Soledad Pérez-Sánchez

Department of Neurology, University Hospital Virgen Macarena, Av. Doctor Fedriani, no. 3, 41008, Seville, Spain

Tel: +34-686995416

Fax: +34-955008055

E-mail: soledad.perez.sanchez@gmail.com

Received: November 20, 2019

Revised: February 13, 2020

Accepted: February 14, 2020

Neurovascular Research Group is part of the Spanish Neurovascular Disease Research Network (INVICTUS+) (RD16/0019/0015).

The authors are grateful for the collaboration of all the hospitals included in the reference unit for endovascular treatment of stroke in Seville and Huelva.

The authors have no financial conflicts of interest. 